\title{
CUTANEOUS MANIFESTATIONS OF DIABETES MELLITUS
}

\author{
Mariaviagulam Vinnarasan'1, Ramasamy Sindhuja², Krishnamoorthy Vinothiney³, G. Balaji ${ }^{4}$ \\ ${ }_{1}^{1}$ Assistant Professor, Department of Dermatology, Thanjavur Medical College. \\ ${ }^{2}$ Associate Professor, Department of Dermatology, Thanjavur Medical College. \\ ${ }^{3} 1^{\text {st }}$ Year Postgraduate Student, Department of Dermatology, Thanjavur Medical College. \\ ${ }^{4}$ Senior Assistant Professor, Department of Neurology, Chengalpattu Medical College.
}

ABSTRACT

\section{BACKGROUND}

Diabetes Mellitus is the most common endocrine disorder. Cutaneous involvement is one of the common manifestations in diabetic population. The knowledge of the pattern and prevalence of cutaneous manifestations in diabetes mellitus will be useful for disease control, early stage treatment, awareness in reducing morbidity of diabetes mellitus patients.

The aim of the study is to determine the pattern and prevalence of cutaneous manifestations in Diabetes mellitus in Thanjavur Medical College in view of increasing prevalence of diabetes mellitus in the present scenario of sedentary life style in general population.

\section{MATERIALS \& METHODS}

This study is a hospital-based descriptive study that includes 1200 self-reporting patients of age group 40 to 70 years with diabetes mellitus who attended the Diabetology OP for the period of 3 months from May 15, 2017 to August 15, 2017 in our medical college situated in South India. A detailed history along with complete systemic and cutaneous examinations were carried out in all patients. Relevant investigations were done wherever necessary.

\section{RESULTS}

Ninety-nine percent of patients were of type 2 Diabetes Mellitus. Cutaneous manifestations were present in $40 \%$ (480 cases). Among 480 cases, Infections (35\%), Diabetic ulcers (20\%), acanthosis nigricans (10\%), others (35\%) were the commonest cutaneous manifestations in Diabetes Mellitus.

\section{CONCLUSION}

Data correlates with previous hospital-based prevalence studies of Cutaneous manifestations in Diabetes mellitus. Whenever patients present with multiple cutaneous manifestations they should be evaluated for diabetes mellitus and its systemic complications.

\section{KEYWORDS}

Diabetes Mellitus Type 1 and type 2, Cutaneous Manifestations.

HOW TO CITE THIS ARTICLE: Vinnarasan M, Sindhuja R, Vinothiney K, et al. Cutaneous manifestations of diabetes mellitus. J. Evolution Med. Dent. Sci. 2017;6(83):5815-5819, DOI: 10.14260/jemds/2017/1262

\section{BACKGROUND}

Diabetes Mellitus is the most common endocrine disorder that affects cardiovascular, renal, nervous systems, eyes and skin. Most of the patients with Diabetes Mellitus will have cutaneous manifestation of known and unknown aetiologies of which known aetiologies are hyperglycaemia \& insulin dysfunction, either directly or through damage to vascular, neurological and immune system.

Cutaneous manifestations are quite common in type 2 Diabetes Mellitus with approximately $40 \%$ of patients experiencing dermatological problems during the course of their illness. Cutaneous signs of Diabetes Mellitus reflect the status of glycaemic control and lipid metabolism. According to published reports, the exact prevalence of cutaneous manifestations of DM in India - 43\%-66\%.

'Financial or Other Competing Interest': None.

Submission 01-09-2017, Peer Review 03-10-2017,

Acceptance 09-10-2017, Published 16-10-2017.

Corresponding Author:

G. Balaji,

No. 33, Devadas Street,

Vedhachala Nagar, Chengalpattu.

E-mail:dhunsi75@gmail.com

DOI: $10.14260 /$ jemds $/ 2017 / 1262$
The information on prevalence and pattern of diabetic dermatoses is important for better understanding of burden, creating awareness and for planning strategies to manage these diseases. This point prevalence study was undertaken to determine the epidemiological pattern and prevalence of cutaneous manifestations in Diabetic patients.

\section{MATERIALS AND METHODS}

This study was a descriptive study on 1200 self-reported patients who attended Diabetology Outpatient Department at Thanjavur Medical College situated in Southern part of India. It was conducted during the period of 3 months from May 15 to August 15, 2017. The study enrolled all patients with no exclusion based on sex, nationality, socioeconomic status. Details like age, sex, onset of disease were recorded. A detailed history was taken in each patient with particular reference to cutaneous conditions including duration, progression and treatment modalities. Blood sugar, urine analysis, glycosylated haemoglobin levels were estimated in all patients to assess the control of diabetes. Liver function tests, renal function tests, lipid profile electrocardiogram, 24 hours urinary protein were done. All patients were evaluated for obesity by calculating body mass index and hypertension by blood pressure monitoring. Histopathological examination 
and microbiological investigations of skin lesions were performed wherever necessary to confirm the diagnosis.

\section{RESULTS}

The proportion of cases with cutaneous manifestations among total diabetic cases attending Diabetology Outpatient Department is as follows:

Among the total number of diabetic patients who attended during this period in Diabetology OPD in Thanjavur Medical College, about 480 diabetic patients were found to have cutaneous manifestations. It comes to about $40 \%$ of total number of cases.

\section{*Sex Ratio}

Of the total 480 patients with cutaneous manifestations, 285 were female, 195 were male (Male:Female ratio was 1:1.5).

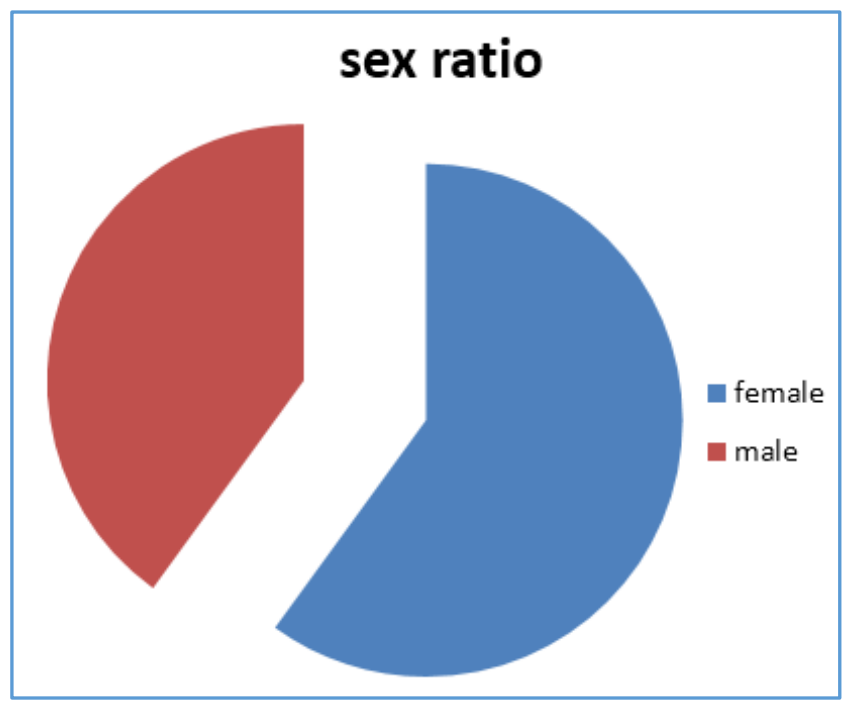

\section{*Age of Onset}

Among 480 cases, the most common age of onset is between 50 to 60 years which is about $40 \%$ of total cases (192 cases) which is in concordance with any other study. 144 cases were between 40 to 50 years (30\%). 72 cases were between 60 to 70 years (15\%). 72 cases were below 30 to 40 years (15\%).

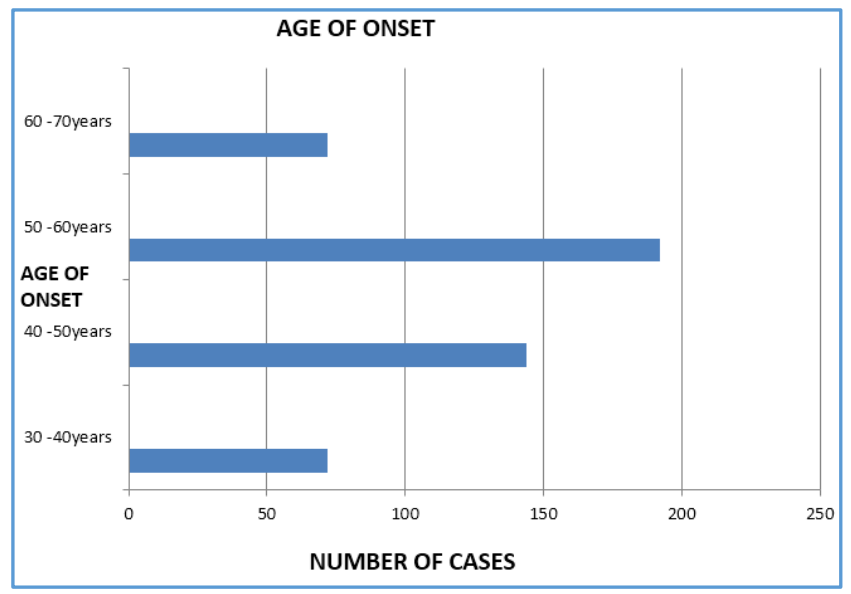

\section{*Duration of Disease}

Among 480 cases, the majority of patients with cutaneous manifestations were having disease duration between 5-10 years $(45 \%)$ followed by $1-5$ years $(30 \%)$, more than 10 years $(15 \%)$, less than 1 year $(10 \%)$.

\section{*Comorbidities}

In Diabetic patients with cutaneous manifestations, 30\% were obese, coronary artery disease was present in $25 \%$, Hypertension was present in $15 \%$, Depression in $10 \%$, Nephropathy in $10 \%$, Neuropathy in $5 \%$, and Retinopathy in $5 \%$.

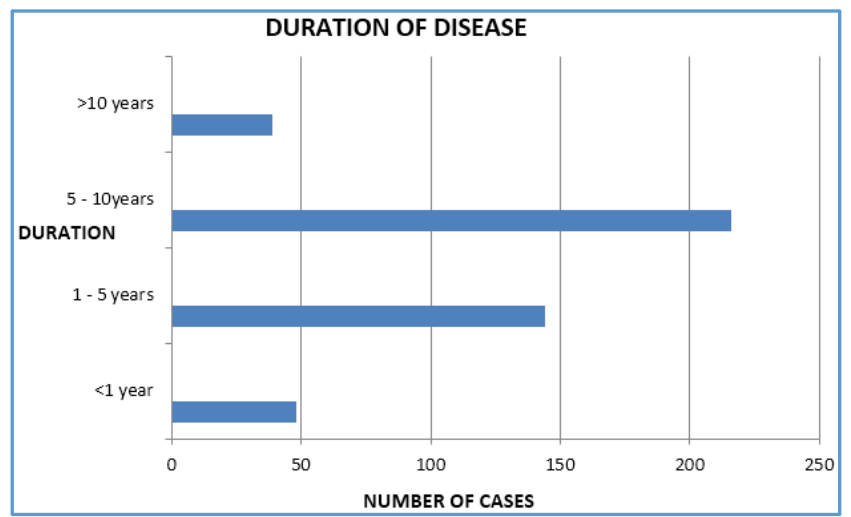

\section{*Glycosylated Haemoglobin Levels}

Out of 480 patients with cutaneous manifestations, $60 \%$ had uncontrolled $\mathrm{HbA}_{1 \mathrm{c}}$ levels and $40 \%$ had controlled $\mathrm{HbA}_{1 \mathrm{c}}$ levels.

\section{*Cutaneous Manifestation in Diabetes Mellitus}

\section{Infections}

Infections constitute the largest group of cutaneous conditions affecting patients with Diabetes Mellitus i.e., $35 \%$ of total number of cases (168 cases).

\section{Bacterial Infections}

Folliculitis, furunculosis, carbuncle, cellulitis, erythrasma, paronychia- totally constitute about 15\% (Around 72 cases).

\section{Fungal Infections}

Fungal infections constitute about $15 \%$ of cases (72 cases) among which candidal infection was present in $5 \%$ of cases, dermatophytic infections were present in $5 \%$ of cases and all the other fungal infections totally constitute about $5 \%$ of cases.

\section{Viral Infections}

Herpes simplex \& Herpes zoster constitute about 5\% (24 cases).

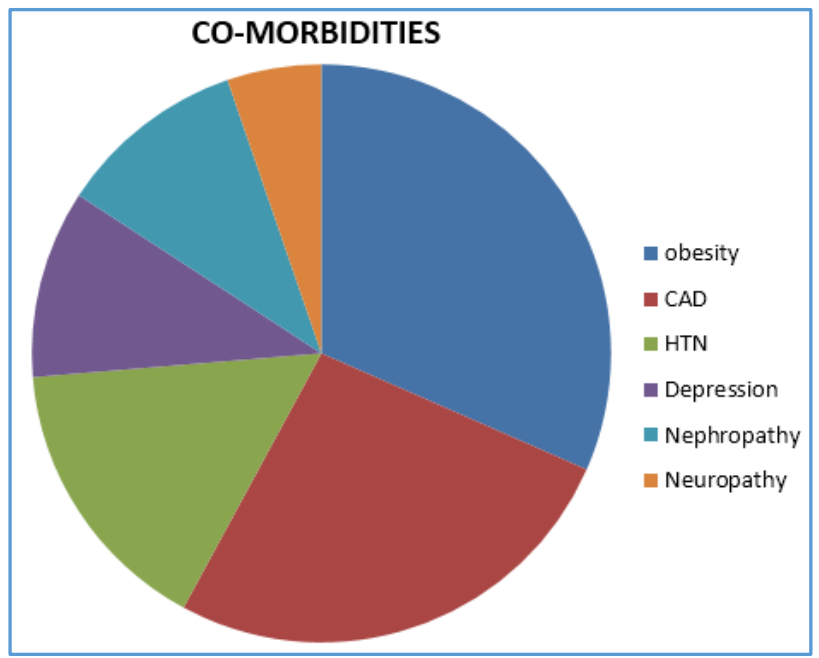




\section{Due To Vascular Damage}

Out of 480 diabetic patients, $20 \%$ had diabetic ulcer, $7 \%$ had diabetic dermopathy, less than $5 \%$ had rubeosis. Known factors associated with foot ulceration in the setting of diabetes include long duration of diabetes (>than 10 years), poor glycaemic control.[1]

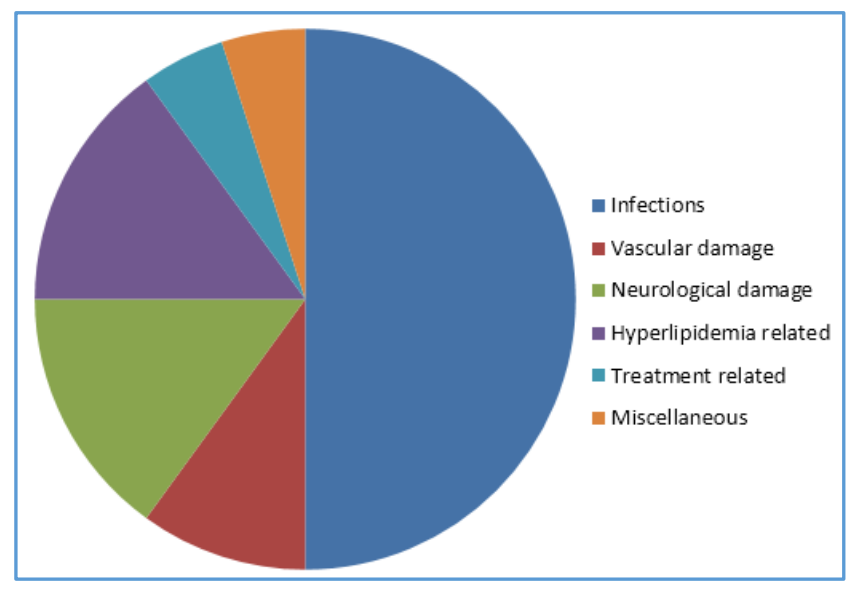

3. Due To Neurological Damage

Approximately, $50 \%$ of patients with diabetes mellitus develop a chronic, symmetrical length dependent sensorimotor polyneuropathy due to damaged endoneurial microvessels.[2] Diabetic Charcot arthropathy in $2 \%$ of cases and diabetic ulcer in $20 \%$ of cases ${ }^{[3]}$ were some manifestations due to neurological damage.

\section{Hyperlipidaemia-related Skin Disease}

Among the total number of diabetic patients with cutaneous manifestations, $50 \%$ of the patients develop skin disease related to hyperlipidaemia of which acanthosis nigricans was present in $10 \%$ of cases, Skin tags and eruptive xanthomas in total constitute about $2 \%$ of cases.

\section{Associated with Treatment}

Treatment-related skin manifestations in diabetes mellitus include Insulin lipodystrophy, allergic reactions to insulin and oral hypoglycaemic drugs.

Among the total number of cases, lipodystrophy, allergy to insulin and allergy to oral hypoglycaemic drugs (most common with sulfonylureas) in total constitute about $3 \%$ of cases.

\section{Miscellaneous}

Pruritus- Localised or generalised pruritus without any skin lesions was present in $7 \%$ of cases. Anogenital pruritus present due to secondary infection with candidiasis.

\section{Cheiroarthropathy}

$4 \%$ of adult patients with type 1 and type 2 diabetes mellitus had cheiroarthropathy. Limited joint mobility correlated with the presence of microvascular disease ${ }^{[4]}$ and levels of glycosylated haemoglobin levels.

\section{Necrobiosis Lipoidica}

$3 \%$ of patients with diabetes mellitus had necrobiosis lipoidica. Most of the patients with necrobiosis lipoidica were females ${ }^{[5]}$ with mean age of onset around 40 years.
Bullous Diabeticorum, Granuloma Annulare, Perforating Dermatoses accounts for up to less than $2 \%$ of the total number of patients with diabetes.

\section{Associated Skin Diseases}

Among the dermatoses associated with increased incidence in diabetes mellitus, psoriasis, lichen planus, vitiligo were present in our study.

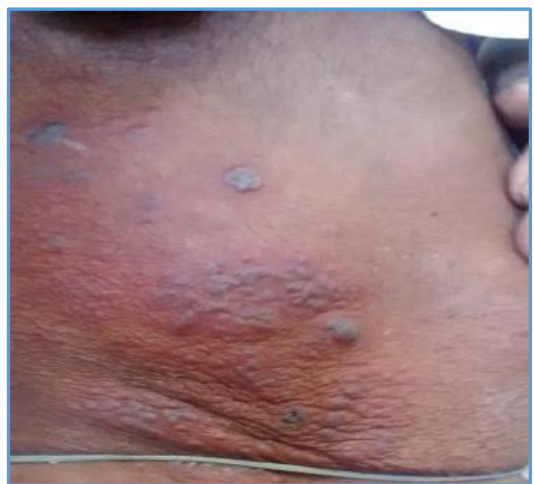

Figure 1. Herpes Zoster

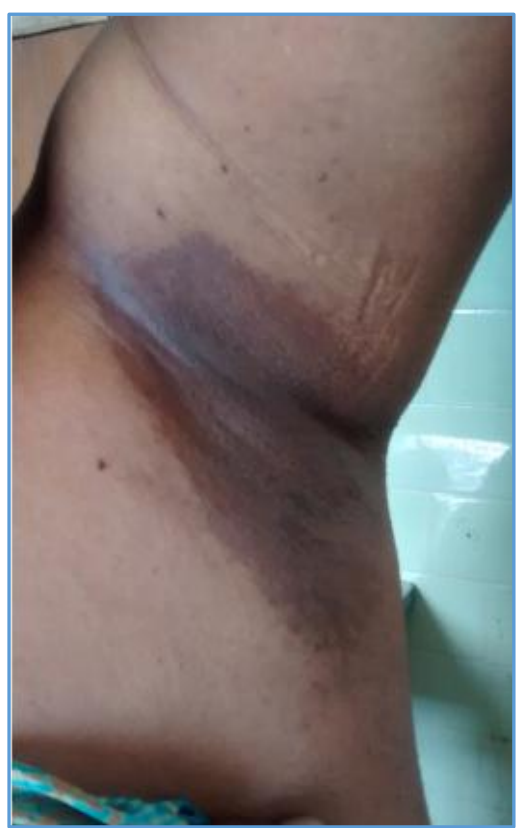

Figure 2. Erythrasma

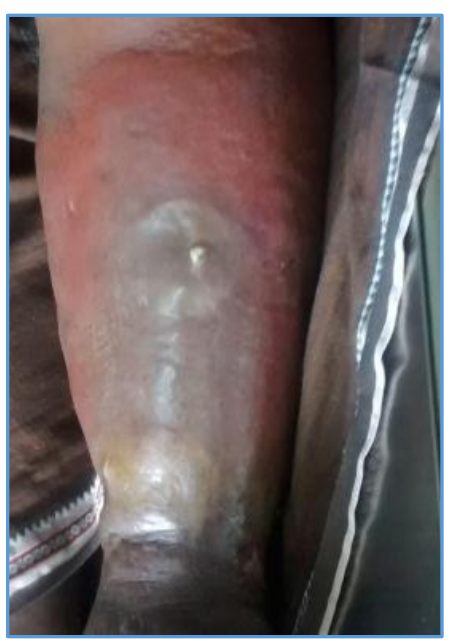

Figure 3. Cellulitis 


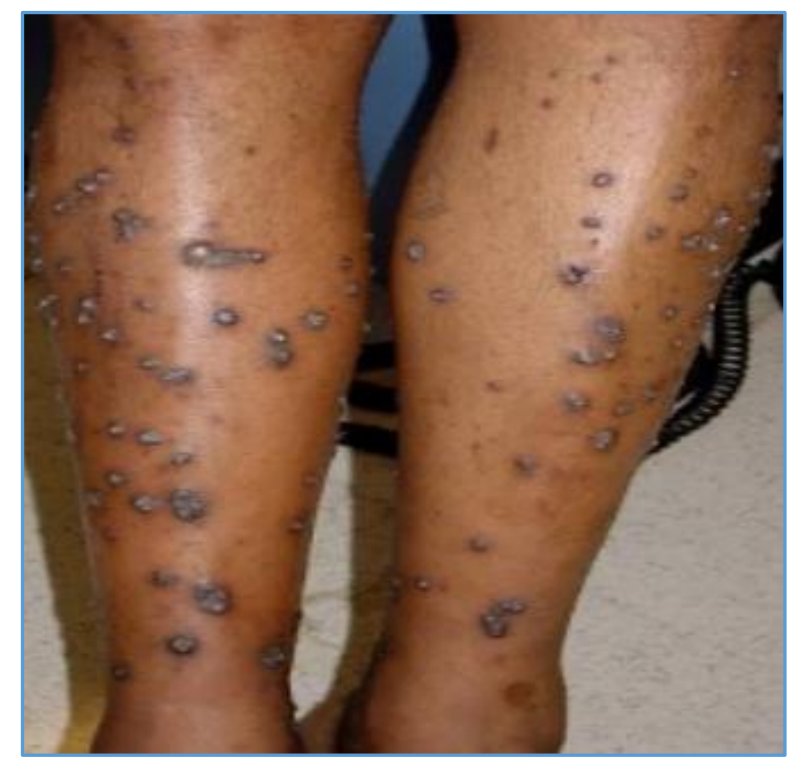

Figure 4. Perforating Dermatoses

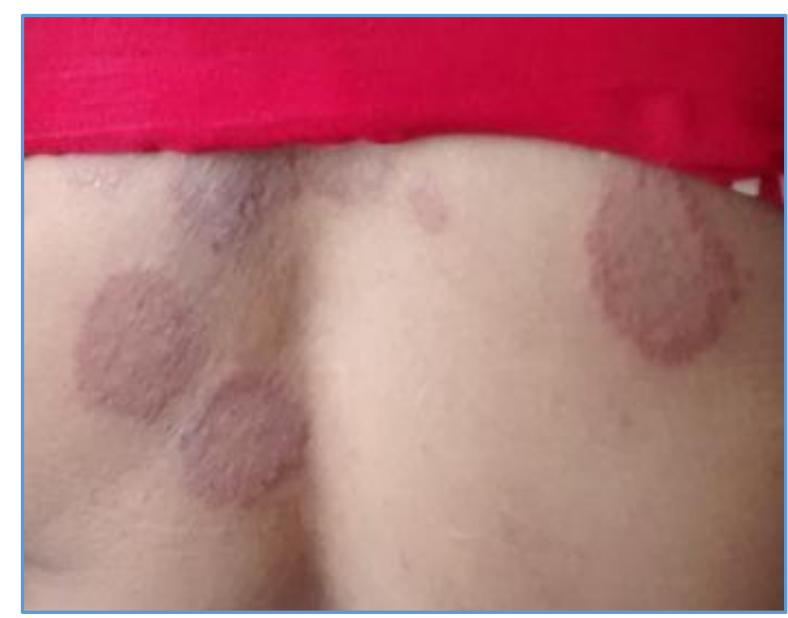

Figure 5. Dermatophytoses

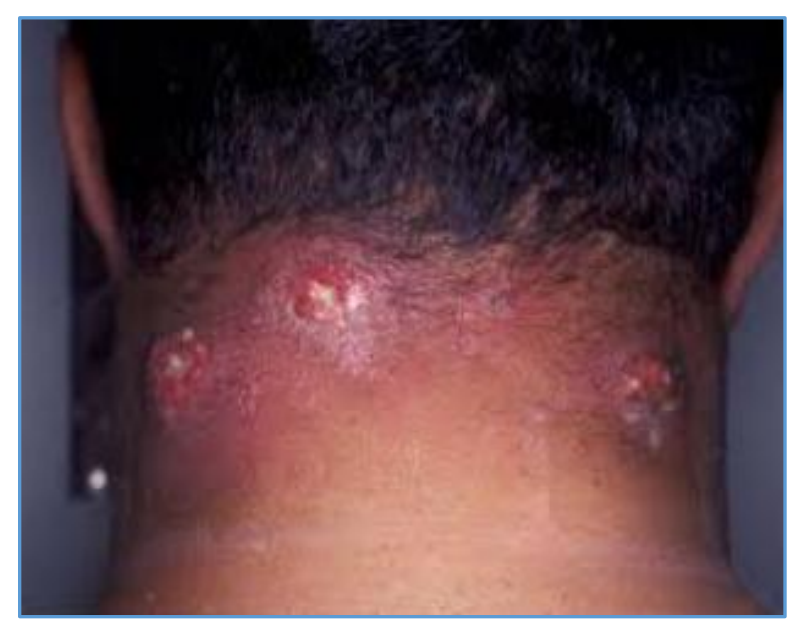

Figure 6. Carbuncle

\section{DISCUSSION}

Diabetes mellitus is the most common endocrine disorder characterised by relative or absolute insulin deficiency leading to gross defects in glucose, fat and protein metabolism. Diabetes mellitus is classified into 4 types-

1. Type 1- Insulin dependent (usually juvenile onset)
2. Type 2- Non-insulin dependent (usually adult onset and associated with obesity)

3. Secondary Diabetes- Iatrogenic or associated with pancreatic, hormonal and genetic disease.

4. Gestational diabetes- Associated with pregnancy.

Tight glycaemic control may have a beneficial effect on diabetic dermatoses.[6] A fasting blood glucose level more than or equal to $126 \mathrm{mg} / \mathrm{dL}$ or a random value of more than or equal to $200 \mathrm{mg} / \mathrm{dL}$ on two separate occasions confirms the diagnosis of diabetes mellitus. Diabetes may also be diagnosed with an $\mathrm{HbA}_{1 \mathrm{c}}$ level more than or equal to 6.5\%.

Majority of patients with diabetes mellitus had cutaneous manifestations. Cutaneous signs usually appear after diabetes is established though in some patients may precede diagnosis by months to years.

Mechanism of many cutaneous manifestations is unknown, while pathogenesis for others is due to hyperglycaemia and insulin dysfunction.

Hyperglycaemia leads to non-enzymatic glycosylation (NEG) of various structural and regulatory proteins including collagen. NEG leads to the formation of advanced glycation end products (AGEs) that are responsible for decrease in both acid solubility and enzymatic digestion of cutaneous collagen. The degree of cutaneous AGEs correlate strongly with retinopathy, nephropathy and other microvascular complications of DM.

Hyperglycaemia also increases the flux through polyol and hexosamine pathways with activation of protein kinase $\mathrm{C}$, $\mathrm{NF}-\mathrm{kB}$, mitogen-activated protein-kinase and other intercellular messengers. The resulting cascade of metabolic events leads to endothelial proliferation, thickened basement membrane with deposits of PAS positive material and narrowing of blood vessels causing vascular complications.

Hyperglycaemia and ketoacidosis diminishes chemotaxis, phagocytosis and bactericidal activity of WBCs resulting in frequent infections.

Infections are the most common diabetic dermatosis. Cutaneous infections include candidiasis (VVC, balanoposthitis, intertrigo, paronychia, oral thrush, angular cheilitis), dermatophytosis, bacterial infections (impetigo, furuncle, carbuncle, erythrasma, malignant otitis externa, necrotising fasciitis), viral infections (Herpes zoster and Herpes simplex).

The action of insulin on insulin like growth factor-1 receptor appears to mediate the abnormal epidermal proliferation resulting in acanthosis nigricans and skin tags. Other members of tyrosine kinase receptors including epidermal growth factor receptor, fibroblast growth factor receptor have been implicated in acanthosis nigricans.

Acanthosis nigricans should be considered a prognostic indicator for developing type 2 diabetes mellitus and is characterised by smooth, velvety, hyperkeratotic, hyperpigmented skin predominantly affecting flexures. Skin tags appear to be a marker of diabetes independent of obesity and acanthosis nigricans and characterised by small, soft, pedunculated lesions occurring on the eyelids, neck and axillae.

Peripheral neuropathy, peripheral vascular disease and intrinsic wound healing disturbances in diabetes contribute to the development of diabetic ulcers. Callus formation precedes necrosis over bony prominences of feet usually on great toe and sole, over first/second metacarpophalangeal 
joints. Complications are soft tissue infections and osteomyelitis.

Diabetic Charcot arthropathy[7] typically presents as a warm, swollen, erythematous foot and ankle, which may mimic cellulitis, It is probably due to combination of motor, sensory, autonomic neuropathy. Circulatory abnormalities, unprotected trauma and abnormal pressure leads to dislocation and fusion of joints, fracture and resorption of bone.

Dysregulation of lipid metabolism in insulin deficient Diabetes mellitus resulting in hypertriglyceridaemia manifesting in skin as eruptive xanthomas. It signifies the risk of developing pancreatitis. The lesions slowly resolve when the diabetes and hyperlipidaemia are properly managed.

Rubeosis presents as rosy reddening of the face and sometimes of the hands and feet, in longstanding cases of diabetes. It has been attributed to microangiopathy or decreased vascular tone.

Cheiroarthropathy presents as tightness and thickening of the skin and periarticular connective tissues of the fingers resulting in painless loss of joint mobility. It initially involves distal interphalangeal joint of fifth digit and progresses proximally to involve all fingers. This disorder is characterised by Prayer sign which is an inability to approximate palmar surfaces and interphalangeal joint spaces with the hands pressed together and fingers separated.

Scleredema diabeticorum presents with insidious onset of painless symmetrical induration and thickening of skin on upper back and neck spreading to face, shoulders and trunk. The skin retains a non-pitting, woody, peau d'orange appearance.

Necrobiosis lipoidica presents as sharply demarcated yellow brown plaques on anterior pretibial region with violaceous irregular border that may be raised and indurated. Over time lesions flatten and a central yellow area becomes atrophic with visible telangiectasias taking on the characteristic Glazed porcelain sheen.

Bullous diabeticorum is characterised by abrupt onset of bullae on the lower extremities. The blisters are usually painless and non-pruritic. Histopathological examination of bulla shows an inconsistent level of separation varying from intraepidermal to subepidermal.[8]

Acquired perforating collagenosis presents as pruritic, keratotic papules mainly on extensor surface of extremities. Many are follicular and contain a prominent central keratotic plug. This has been reported in patients with diabetes with and without renal insufficiency. It is attributed to glycation of collagen and minor injury such as pressure or scratching. [9]

Finger pebbles are multiple, grouped, minute papules on extensor surface fingers in or near the knuckle-pads or periungual region. They are more common in patients with diabetes mellitus.

Yellow skin and nails are frequent in patients with diabetes mellitus with a questionable relationship to carotene.[10]

Diabetes is more common in patients with psoriasis probably due to its association with insulin resistance in the metabolic syndrome. There are indirect associations between diabetes and both calciphylaxis and nephrogenic fibrosing dermopathy related to diabetic nephropathy.

\section{CONCLUSION}

Our cohort of patients showed a similar clinical profile and outcome as our Indian Diabetic population. Our study confirmed high prevalence of skin disorder in diabetes mellitus patients, showing that careful dermatological examination and outpatient follow-up of diabetic patients is required to provide them adequate skin management, thus reducing morbidity and complications related to skin. More research and detailed prospective studies need to be done to delineate the natural course of the disease which varies in different individuals and also according to the clinical pattern of the disease. A prerequisite would be that risk factors are identified in a consistent and reliable way. Also, there is a need for more effective targeted therapy for a better outcome.

\section{REFERENCES}

[1] Boyko EJ, Ahroni JH, Cohen V, et al. Prediction of diabetic foot ulcer occurrence using commonly available clinical information: The Seattle Diabetic Foot Study. Diabetes Care 2006;29(6):1202-7.

[2] Tesfaye S, Boulton AJ, Dyck PJ, et al. Diabetic neuropathies: update on definitions, diagnostic criteria, estimation of severity and treatments. Diabetes Care 2010;33(10):2285-93.

[3] Singh N, Armstrong DG, Lipsky BA. Preventing foot ulcers in patients with diabetes. JAMA 2005;293(2):217-28.

[4] Rosenbloom AL, Silverstein JH, Lezotte DE, et al. Limited joint mobility in childhood diabetes mellitus indicates increased risk for microvascular disease. $\mathrm{N}$ Engl J Med 1981;305(4):191-4.

[5] Muller SA, Winkelmann RK. Necrobiosis lipoidica diabeticorum. A clinical and pathological investigation of 171 cases. Arch Dermatol 1966;93(3):272-81.

[6] Skyler JS, Bergenstal R, Bonow RO, et al. Intensive glycemic control and the prevention of cardiovascular events: implications of the accord, advance, and va diabetes trials. A position statement of the American Diabetes Association and a scientific statement of the American College of Cardiology Foundation and the American Heart Association. Diabetes Care 2009;32(1):187-92.

[7] Wukich DK, Sung W. Charcot arthropathy of the foot and ankle: modern concepts and management review. J Diabetes Complications 2009;23(6):409-26.

[8] Toonstra J. Bullosis diabeticorum. Report of a case with a review of the literature. J Am Acad Dermatol 1985;13(5 Pt 1):799-801.

[9] Cox NH. Diabetes and the skin: an update for dermatologists. Expert Rev Dermatol 2007;2:305-16.

[10] Huntley AC. The cutaneous manifestations of diabetes mellitus. J Am Acad Dermatol 1982;7(4):427-55. 